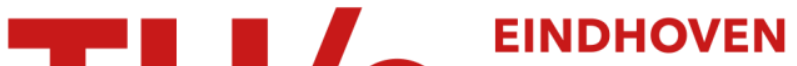

\section{Maintenance scheduling for railway tracks under limited possession time}

\section{Citation for published version (APA):}

Dao, C., Basten, R., \& Hartmann, A. (2018). Maintenance scheduling for railway tracks under limited possession time. Journal of Transportation Engineering Part A: Systems, 144(8), [04018039].

https://doi.org/10.1061/JTEPBS.0000163

\section{Document license:}

TAVERNE

DOI:

10.1061/JTEPBS.0000163

Document status and date:

Published: 01/08/2018

\section{Document Version:}

Publisher's PDF, also known as Version of Record (includes final page, issue and volume numbers)

\section{Please check the document version of this publication:}

- A submitted manuscript is the version of the article upon submission and before peer-review. There can be important differences between the submitted version and the official published version of record. People interested in the research are advised to contact the author for the final version of the publication, or visit the $\mathrm{DOI}$ to the publisher's website.

- The final author version and the galley proof are versions of the publication after peer review.

- The final published version features the final layout of the paper including the volume, issue and page numbers.

Link to publication

\section{General rights}

Copyright and moral rights for the publications made accessible in the public portal are retained by the authors and/or other copyright owners and it is a condition of accessing publications that users recognise and abide by the legal requirements associated with these rights.

- Users may download and print one copy of any publication from the public portal for the purpose of private study or research.

- You may not further distribute the material or use it for any profit-making activity or commercial gain

- You may freely distribute the URL identifying the publication in the public portal.

If the publication is distributed under the terms of Article 25fa of the Dutch Copyright Act, indicated by the "Taverne" license above, please follow below link for the End User Agreement:

www.tue.nl/taverne

Take down policy

If you believe that this document breaches copyright please contact us at:

openaccess@tue.nl

providing details and we will investigate your claim. 


\title{
Maintenance Scheduling for Railway Tracks under Limited Possession Time
}

\author{
Cuong Dao'; Rob Basten²; and Andreas Hartmann ${ }^{3}$
}

\begin{abstract}
Maintenance planning for busy railway systems is challenging because there is growing pressure on increasing operation time, which reduces the infrastructure-accessible time for maintenance. This paper proposes an optimization model that is aimed at finding the best maintenance schedule for multiple components in a railway track to minimize the total cost in the planning horizon. One distinct and practical feature of the model is that the track accessible time for maintenance is limited. We formulate all relevant costs in the component's life cycle, including maintenance cost, fixed track-closure (possession) cost, social-economic cost related to the effects of maintenance time on the train operation, and service-life shortening cost due to the shifting of activities. Generally, it is beneficial to cluster and maintain several components in a single possession because this helps reduce the cost by occupying the track only once. However, the decision must depend on the available possession time. A sensitivity analysis is performed to highlight the effects of available possession time on the number of required possessions as well as the total cost incurred. DOI: 10.1061/JTEPBS.0000163. ( $\odot 2018$ American Society of Civil Engineers.
\end{abstract}

\section{Introduction}

Maintenance of infrastructure is crucial for a safe and wellfunctioning railway system. The process of deciding what, when, and how infrastructure maintenance should best be performed is a vital part of ensuring efficient operation. However, this is a complex planning problem because these decisions need to take several factors into consideration, such as track degradation, traffic condition, available resources, and other tangible and intangible issues (Uzarski and McNeil 1994). In large and extensively used railway networks, such as those in the United States, United Kingdom, and continental Europe, maintenance planning is more challenging because a great amount of railway infrastructure is a mix of old and recently built assets that are often associated with a high demand for maintenance and under pressure to increase operation time.

Railway infrastructure maintenance activities can be classified into two types: routine or ordinary maintenance, such as regular inspections and minor repairs, and major maintenance and renewal, such as rail grinding, ballast tamping, and renewal. These maintenance activities are performed in a track closure period called possession (Cheung et al. 1999; Higgins 1998; Budai 2009; Lidén 2015). Ordinary maintenance activities require a relatively short time to execute and are often scheduled in a minor possession. Major maintenance and renewal activities require a longer time to execute and are thus scheduled in a major possession. Planning of a minor possession is not difficult because minor inspections and repairs can be done at night or in a period between two consecutive

${ }^{1}$ Postdoctoral Researcher, Dept. of Construction Management and Engineering, Univ. of Twente, P.O. Box 217, Enschede 7500 AE, Netherlands (corresponding author). ORCID: https://orcid.org/0000-0002 -3322-1243. Email: c.dao@utwente.nl

${ }^{2}$ Associate Professor, Dept. of Industrial Engineering and Innovation Sciences, Eindhoven Univ. of Technology, P.O. Box 513, Eindhoven $5600 \mathrm{MB}$, Netherlands.

${ }^{3}$ Associate Professor, Dept. of Construction Management and Engineering, Univ. of Twente, P.O. Box 217, Enschede 7500 AE, Netherlands.

Note. This manuscript was submitted on October 23, 2017; approved on February 16, 2018; published online on May 29, 2018. Discussion period open until October 29, 2018; separate discussions must be submitted for individual papers. This paper is part of the Journal of Transportation Engineering, Part A: Systems, (C) ASCE, ISSN 2473-2907. trains, which usually does not affect train operation (Lidén 2015). However, planning a major possession is more complex because it affects train operation and involves several parties, including the rail infrastructure manager, train operating company, traffic control, and maintenance contractors. Thus, multiple and long possessions may have severe impacts on regular train timetables, and major maintenance and renewal jobs are often combined or clustered to reduce the total costs. This paper mainly focuses on the scheduling of major maintenance and renewal activities of components in a rail track system.

In this paper, the railway track is regarded as a system consisting of several components such as rail, ballast, sleepers, and switches, and our maintenance planning model considers all of these components simultaneously. Maintenance includes preventive maintenance (PM) and renewal. The former includes activities that restore the track components to a better condition such as rail grinding, ballast cleaning, tamping, and so on, and the latter is regarded as the replacement of components when maintaining them is no longer practical and economical (Levy 2012). A PM activity can help restore the component to a better condition, and it is often cheaper than a renewal of that component. Very frequently, a PM activity can be done several times on the same component prior to a renewal to use the cost advantage of PM. An example of PM is "rail surfacing," which can help improve the rail surface condition at a specific maintenance cost, but after a certain number of surfacing activities, the rail thickness can no longer sustain another surfacing, and a renewal at a much higher cost is needed. Generally, components can have different intervals of performing PM activities, and renewal is needed when a fixed number of PM activities have been performed. In this paper, we assume that the component has a worn-out stock that can be represented by the number of PM activities applied on it. After a PM, the component is in a good condition, but not "as good as new," and the stock for the number of remaining PM activities to the next renewal decreases. After a renewal, the component is assumed to be "as good as new" and the number of remaining PM activities is reset to the maximum number; that is, the same life cycle is repeated.

In a highly used transportation system, the task of assigning a busy track for maintenance and train operation is a critical issue (Lidén and Joborn 2016). The infrastructure accessible time for 
maintenance is often tightened to a specified window. For example, in Hong Kong and Singapore, the maintenance window is $3-5 \mathrm{~h}$ at night; in the Netherlands, ordinary maintenance activities are performed at night within a maintenance window of 4-5 h. Major possessions are often limited to 1 or 2 days depending on how busy the track location is, and they are scheduled at a time when the impact on the train operation is less severe, for example, weekends and holidays.

In this paper, we present a maintenance scheduling optimization model for multiple components in a railway track and formulate it as a binary integer programming (IP) model. The novelty of the proposed model is that the time needed for maintenance is incorporated in the railway maintenance problem and the limitation of possession time is modeled for the first time. This is, today, very critical for busy railway systems, where the demand for train operation is very high and there is growing pressure to increase operation time, thus reducing the infrastructure accessible time for maintenance. In addition, two new ways of modeling the cost related to the impact of possession on operation that values the customers and the service-life shortening resulting from clustering maintenance activities are proposed. The model can help maintenance managers in determining the most cost-effective maintenance and renewal schedule for several components in the same railway track.

\section{Literature Review}

The existing literature on railway infrastructure maintenance scheduling can be classified into three categories. The first category concentrates on railway component degradation modeling and maintenance interval determination for a single component or type of maintenance activity. Ballast tamping is referred to as a preventive maintenance activity in a number of studies (Zhao et al. 2006; Andrade and Teixeira 2011; Caetano and Teixeira 2016; Vale et al. 2012). A life cycle cost approach for ballast tamping and renewal was presented in Zhao et al. (2006). Vale et al. (2012) and Caetano and Teixeira (2016) used track geometry degradation and tamping recovery quality modeling to determine the tamping schedule. Andrade and Teixeira (2011) studied the same problem, but with a multiobjective optimization approach of minimizing both the costs of maintenance and train delay. The overhead contact line is analyzed to identify the best inspection frequency with a consideration of the criticality of components and area as well as the availability of inspection teams (Zorita et al. 2010). Although the models in this category can provide useful information and maintenance plans for a single type of component, there is a critique that these models have considered neither the track system as a whole nor the advantages of maintaining multiple components together.

In the second category, maintenance scheduling is considered a "resource allocation" or "resource assignment" problem where maintenance jobs and resources, such as maintenance manpower and available time slots, are the inputs, and maintenance schedulers need to assign the jobs to available resources as much as possible. Higgins (1998) considered maintenance scheduling as a joballocation problem in which the maintenance activities should be assigned to a given set of crews. Meanwhile, Cheung et al. (1999) regarded railway maintenance as a time-allocation problem; that is, they aimed to assign as many maintenance jobs as possible to the available time slots. Focusing on maintenance crew scheduling, Gorman and Kanet (2010) formulated it as a job-shop scheduling problem. In a more recent paper, Peng and Ouyang (2014) presented a special approach for modeling the railway maintenance planning problem. It was modeled as a vehicle routing problem, where the maintenance crews were considered "vehicles," and there was a set of projects with several jobs in each project being regarded as "routes." A vehicle, that is, a maintenance crew, needs to travel to several routes, that is, jobs in the projects, in such a way that all the routes are covered and the total traveling cost is minimized. A drawback of the models in this category is that the number of maintenance tasks, crews, and available time slots in the allocation problem are fixed. Thus, these models are difficult to extend to a long-term planning problem where a maintenance task can be performed at any time in the planning horizon.

In the last category, the aim of railway maintenance scheduling is to find the time periods to perform maintenance activities for components with different maintenance intervals. In general, maintenance requires several setup activities, and it is more economical to maintain several components at the same time to reduce the number of possessions and spend the setup cost only once. The problem of maintenance planning for rail-track components belongs to a general maintenance class of multicomponent systems with economic dependence (Dekker et al. 1997; Nicolai and Dekker 2008; Dao et al. 2014). Budai et al. (2006) formulated a preventive maintenance scheduling problem for repetitive routine works and renewal projects. A mathematical programming model is presented to minimize the total maintenance and possession costs in a finite planning horizon. Pouryousef et al. (2010) extended the Budais model by considering the planning of multiple segments at the same time. Zhao et al. (2009) and Pargar et al. (2017) studied the maintenance scheduling problem and considered multiple types of cost savings due to joint maintenance and renewal activities at multiple segments. The types of saving depend on the number of adjacent segments and the share of special machineries for maintenance. Focusing on the renewal of track components, Caetano and Teixeira (2013) optimized the components' life cycle cost and the unavailability of track when it is available for maintenance.

In this paper, we study the last category of the railway maintenance scheduling problem and address a situation where the possession time is limited. To our best knowledge, no paper in this category considers the limitation of possession time and its effects on the maintenance scheduling problem. By investigating the limitation of possession time, this paper can provide a solution for infrastructure managers of busy railway networks where there is an increasing demand for using the track for train-path operation and where a shrinking time window is available for infrastructure maintenance. In addition, the existing maintenance planning models assume that a fixed possession cost is incurred when at least one activity is performed in a time period regardless of the number of activities to be clustered in that period. In fact, the possession cost varies depending on the possession time as well as the "social-economic" impacts, that is, the expected number of customers and the cost per customer per hour of the track location. Additionally, when different maintenance activities are clustered in the same time period, it is often seen that a component is maintained or renewed in a period that is earlier than its recommended time. In this case, the service life of the component is shortened compared to the service life when its recommended maintenance interval is used. Thus, we also consider a service life shortening cost due to early maintenance of components.

The maintenance scheduling problem is considered in a finite planning horizon using a rolling-horizon approach (Wildeman et al. 1997). In the rolling-horizon approach, the decision is made at the horizon starting time. At the end of the current horizon, the same planning horizon can be repeated, or if there is an information update, the scheduling model generates a new horizon using updated input, and so on. This approach is practical when fixed-term planning is required and the information may be updated, or when the necessity of another planning term needs to be taken into consideration 
Table 1. Input and output of the railway maintenance scheduling problem

\begin{tabular}{|c|c|}
\hline Input & Output \\
\hline $\begin{array}{l}\text { Component PM interval and elapsed } \\
\text { periods }\end{array}$ & $\begin{array}{l}\text { Time of doing each } \\
\text { maintenance activity }\end{array}$ \\
\hline Number of PMs between two renewals & $\begin{array}{l}\text { Time of doing each renewal } \\
\text { activity }\end{array}$ \\
\hline PM cost and time per component & Total maintenance cost \\
\hline Renewal cost and time per component & Total renewal cost \\
\hline $\begin{array}{l}\text { Service life shortening cost per } \\
\text { component }\end{array}$ & Total service life shortening cc \\
\hline Cost per possession & Total possession cost \\
\hline Available possession time & Total number of possessions \\
\hline
\end{tabular}

\section{Problem Formulations}

In this section, we first provide a general problem statement of the railway maintenance scheduling problem under limited possession time. Then, we formulate four cost factors: maintenance and renewal cost, fixed possession cost, social-economic cost, and service life shortening cost. Several constraints that a maintenance scheduler needs to consider are also discussed.

\section{Problem Statement}

In the railway maintenance scheduling problem, we have to schedule PM and renewal activities for a track system consisting of $N$ components in a discrete planning horizon $T$ with a time index $t=1,2, \ldots, T$. Each component $i, i=1,2, \ldots, N$ in the system has its recommended PM interval, that is, the maximum number of time periods between two consecutive PMs, denoted by $\tau_{p, i}$. A renewal is required on the component after a maximum number of PMs, denoted by $N_{p, i}$, have been done. In the railway maintenance scheduling problem, both $\tau_{p, i}$ and $N_{p, i}$ are assumed to be known. Other input data include the time and cost of each maintenance activity, the cost of shifting activities to an earlier period (service life shortening cost), the number of time periods elapsed from the last PM, the number of PM activities from the last renewal, and the available possession time. We need to determine the time periods to perform activities so that the total cost incurred in the planning horizon is minimized. A detailed summary of input and output of the railway maintenance scheduling problem in this paper is presented in Table 1.

The problem is formulated as a binary IP model. The main reason that binary IP is selected for modeling the problem is that it is appropriate for the type of railway maintenance scheduling problem studied in the paper. In this study, the objective is to find the time period to perform a preventive maintenance or renewal activity. By defining binary decision variables based on whether to do an activity at each time period, a solution that contains binary values for all periods in the planning horizon can be easily transferred to a maintenance schedule as required for the problem. The formulation of the railway maintenance scheduling problem is focused mainly on different cost elements and constraints in the planning horizon, which are further explained in the remaining parts of this section.

\section{Maintenance and Renewal Cost and Time}

In the planning horizon $T$, two binary variables are defined as follows:

$$
\begin{aligned}
& x_{i, t}^{m}=\left\{\begin{array}{ll}
1 & \text { if component } i \text { is maintained in period } t \\
0 & \text { otherwise }
\end{array}\right\}, \\
& \forall i=1,2, \ldots, N \\
& \text { (C) ASCE }
\end{aligned}
$$

$$
\begin{aligned}
& x_{i, t}^{r}=\left\{\begin{array}{ll}
1 & \text { if component } i \text { is renewed in period } t \\
0 & \text { otherwise }
\end{array}\right\}, \\
& \forall i=1,2, \ldots, N
\end{aligned}
$$

It is clear that the maintenance schedule for the track system with $N$ components can be realized if the set $\left\{x_{i, t}^{m}, x_{i, t}^{r}\right\}$ is explicitly determined with $\forall i=1,2, \ldots, N$. In a time index $t$, a component cannot be maintained or renewed more than one time. Let $c_{i, t}^{m}$ and $c_{i, t}^{r}$ be the maintenance and renewal costs of component $i$ in period $t$, respectively. The total costs of maintenance and renewal for $N$ components in $T$ time periods are simply the summation of all individual component maintenance costs in each period. They are shown in Eqs. (3) and (4)

$$
\begin{gathered}
C_{M}=\sum_{i=1}^{N} \sum_{t=1}^{T} c_{i, t}^{m} \times x_{i, t}^{m} \\
C_{R}=\sum_{i=1}^{N} \sum_{t=1}^{T} c_{i, t}^{r} \times x_{i, t}^{r}
\end{gathered}
$$

Similarly, denote $t_{i, t}^{m}$ and $t_{i, t}^{r}$ as the maintenance and renewal times of component $i$ in period $t$. It is assumed that the maintenance and renewal activities are performed sequentially in a possession. Then, the possession time for maintenance of all components in period $t$ is calculated as in Eq. (5)

$$
T_{t}=\sum_{i=1}^{N}\left(t_{i, t}^{m} \times x_{i, t}^{m}+t_{i, t}^{r} \times x_{i, t}^{r}\right)
$$

\section{Possession and Social-Economic Costs}

In period $t$, if a maintenance or renewal is performed on at least one component, a track possession is needed to ensure that the track is available for maintenance and no trains can enter the maintenance area. We define the following binary variable:

$$
\begin{aligned}
& x_{t}^{p}=\left\{\begin{array}{ll}
1 & \text { if there is a possession in period } t \\
0 & \text { otherwise }
\end{array}\right\}, \\
& \forall i=1,2, \ldots, N
\end{aligned}
$$

We have

$$
\begin{aligned}
x_{t}^{p} & =\max _{\forall i}\left\{x_{i, t}^{m}, x_{i, t}^{r}\right\} \quad \text { or } \quad\left\{x_{t}^{p} \geq x_{i, t}^{m} \text { and } x_{t}^{p} \geq x_{i, t}^{r}\right\}, \\
\forall i & =1,2, \ldots, N
\end{aligned}
$$

In a period, if the track is needed for maintenance, that is, at least one maintenance or renewal activity is performed, a fixed possession cost $c_{P}^{0}$ is incurred (in this notation, $P$ stands for possession). The variable $c_{P}^{0}$ represents the cost of having a track section for maintenance, which is thus not available for train service. This concept is similar to the definition of possession cost in Budai et al. (2006), and it includes the cost of isolating the track section such as possession booking, retimetabling, and all relevant setup costs that are needed before the maintenance crew can work on the track. In addition, there is a social-economic impact that depends on the duration of possession, which can be modeled as a social-economic cost, that is, a variable cost in the possession. Let the expected number of customers in period $t$ and the cost per customer per unit time be $N_{t}^{C}$ and $c_{P}^{e}$, respectively. The cost per customer per unit time is independent from component maintenance cost and is a new concept in this paper. This cost takes into account the effect of the train service disruption on customers, that is, they have to reroute and 
need extra hours to travel; it may also include "indirect" costs such as reputation loss, decreased customer satisfaction, and losses of future customers due to disruptions. The total fixed possession cost $C_{P}^{f}$ and social-economic $\operatorname{cost} C_{P}^{e}$ in the entire planning horizon are calculated as in Eqs. (8) and (9), respectively

$$
\begin{gathered}
C_{P}^{f}=\sum_{t=1}^{T} c_{P}^{0} \times x_{t}^{p} \\
C_{P}^{e}=\sum_{t=1}^{T} c_{P}^{e} \times N_{t}^{C} \times \sum_{i=1}^{N} T_{t} \\
=\sum_{t=1}^{T} c_{p}^{e} \times N_{t}^{C} \times \sum_{i=1}^{N}\left(t_{i, t}^{m} \times x_{i, t}^{m}+t_{i, t}^{r} \times x_{i, t}^{r}\right)
\end{gathered}
$$

Not all costs are easy to gather. However, a great deal of money is involved in rail infrastructure maintenance (Lidén 2015), and it is worthwhile to spend resources and acquire the cost data in practice. Regarding the possession cost, it can be obtained by general accounting data sharing between railway infrastructure manager, traffic planning, and railway train operators. On the other hand, the cost per customer per unit time greatly depends on how the railway companies value their customers, and the infrastructure manager has to discuss this with railway train services in order to quantify this value.

\section{Service Life Shortening Cost}

Each component $i$ in the system has its recommended PM interval, that is, the maximum number of time periods between two consecutive PMs $\tau_{p, i}$ and the maximum number of PM activities before its renewal $N_{p, i}^{p}$. If the component is considered individually, its PM and renewal activities should be performed exactly in the due time period. However, when components are considered simultaneously, it is more economical to cluster and jointly maintain several components in the same time period. As a result, PM and renewal activities of a component may be performed earlier than its individual due time, and this will reduce the service life of the component compared to its service life in the individual schedule.

In this paper, we define an original schedule as the schedule obtained by directly using the individual PM intervals and the maximum number of PM activities to schedule maintenance and renewal of each component. Because $\tau_{p, i}$ and $N_{p, i}$ are given, the set of $\left\{x_{i, t}^{m_{0}}, x_{i, t}^{r_{0}}\right\}$, which corresponds to the decision to do PM and renewal activities in the original schedule, can be explicitly determined for all $i=1,2, \ldots, N$ and $t=1,2, \ldots, T$.

Denote $c_{i}^{s}$ as the service life shortening cost per time period of component $i$; that is, a cost of $c_{i}^{s}$ is realized if a maintenance activity is performed a period earlier than the recommended period. This cost takes into account using the track until its end of service life as much as possible and preventing too-early maintenance and renewal of rail-track components. Considering all components in the system, the total service life shortening cost of a current schedule with $\left\{x_{i, t}^{m}, x_{i, t}^{r}\right\}$ is presented in Eq. (10)

$$
\begin{aligned}
C_{S}= & \sum_{i=1}^{N} c_{i}^{s}\left\{\tau_{p, i} \sum_{t=1}^{T}\left(x_{i, t}^{m}-x_{i, t}^{m_{0}}\right)+\sum_{t=T-\tau_{p, i}+1}^{T}(T-t)\left(x_{i, t}^{m}-x_{i, t}^{m_{0}}\right)\right. \\
& \left.+\sum_{t=T-\tau_{p, i}+1}^{T}(T-t)\left(x_{i, t}^{r}-x_{i, t}^{r_{0}}\right)\right\}
\end{aligned}
$$

Eq. (10) implies that the total service life shortening cost of each component is equal to a product of the service life shortening cost per time period and the total number of periods shortened due to the maintenance and renewal of that component. The first term in the curly brackets represents the number of periods shortened if the number of PM actions on component $i$ in the current schedule is greater than that in the original schedule. This newly introduced term is critical in reducing the possibilities of having additional PM activities when the planning horizon is shorter than the asset's life cycle. The second and third terms take into consideration the number of periods in the last PM cycle, that is, from $T-\tau_{p, i}+1$ to $T$, and offset the difference between the times to do the last activity in the two schedules. These two terms can play a similar role as in Budai et al. (2006) to value the last PM interval and schedule the last PM and renewal activity as late as possible.

\section{Total Cost in the Planning Horizon}

In summary, the total cost in the whole planning horizon, that is, the objective function to be minimized, is presented as in Eq. (11)

$$
C=C_{M}+C_{R}+C_{P}^{f}+C_{P}^{e}+C_{S}
$$

\section{Sets of Constraints in the Railway Maintenance Scheduling Problem}

The following constraints are considered in this paper.

- Latest possible time to do preventive maintenance activities: This set of constraints ensures that the PM activities are performed within the specified PM interval.

- Latest possible time to do renewal activities: This set of constraints ensures that a renewal activity is performed once the number of PMs reaches its limit.

- Maximum available time in each possession: This set of constraints guarantees that the activities are performed within the available time of blocking a railway section for maintenance.

- Variable constraints.

In the first and second sets of constraints, the first preventive maintenance and renewal activities need to be performed earlier than the regular interval if the asset is not new at the start of the planning horizon, that is, time $t=0$. Let $\tau_{p, i}^{0}$ and $N_{p, i}^{0}$ be the number of periods and PM activities elapsed from the last PM or renewal of component $i$. The first maximum intervals of doing PM and renewal for component $i$ are presented as in Eqs. (12) and (13), respectively

$$
\begin{gathered}
\tau_{p, i}^{1}=\tau_{p, i}-\tau_{p, i}^{0} \\
\tau_{r, i}^{1}=\tau_{p, i} \times\left(N_{p, i}-N_{p, i}^{0}\right)-\tau_{p, i}^{0}
\end{gathered}
$$

The available possession time constraint is critical for a busy railway system where maintenance planners have to coordinate with train operators to reserve the track for maintenance. Because the demand for operation is very high, too-long possessions are not desirable, and the train operation usually limits the time for possession on the railway track, for example, 1 day a week or 2 days a month.

The mathematical formulations of each constraint are presented in the following section.

\section{Railway Maintenance Scheduling Optimization Model}

The railway maintenance scheduling problem under a limitation of available possession time is formulated as a IP model. Details are as follows: 


$$
\begin{aligned}
\operatorname{Min} C= & \sum_{i=1}^{N} \sum_{t=1}^{T} c_{i, t}^{m} \times x_{i, t}^{m}+\sum_{i=1}^{N} \sum_{t=1}^{T} c_{i, t}^{r} \times x_{i, t}^{r}+\sum_{t=1}^{T} c_{P}^{0} \times x_{t}^{p}+\sum_{t=1}^{T} c_{P}^{e} \times N_{t}^{C} \times \sum_{i=1}^{N}\left(t_{i, t}^{m} \times x_{i, t}^{m}+t_{i, t}^{r} \times x_{i, t}^{r}\right) \\
& +\sum_{i=1}^{N} c_{i}^{s}\left\{\tau_{p, i} \sum_{t=1}^{T}\left(x_{i, t}^{m}-x_{i, t}^{m_{0}}\right)+\sum_{t=T-\tau_{p, i}+1}^{T}(T-t)\left(x_{i, t}^{m}-x_{i, t}^{m_{0}}\right)+\sum_{t=T-\tau_{p, i}+1}^{T}(T-t)\left(x_{i, t}^{r}-x_{i, t}^{r_{0}}\right)\right\}
\end{aligned}
$$

Subject to

$$
\begin{aligned}
& \sum_{t=1}^{\tau_{p, i}^{1}} x_{i, t}^{m} \geq 1, \quad \forall i=1,2, \ldots, N \\
& \sum_{t=1+k}^{\tau_{p, i}+k} x_{i, t}^{m} \geq 1, \quad \forall i=1,2, \ldots, N ; \quad k=1,2, \ldots, T-\tau_{p, i} \\
& \sum_{t=1}^{\tau_{r, i}^{1}} x_{i, t}^{r} \geq 1, \quad \forall i=1,2, \ldots, N \\
& \sum_{t=1+k}^{\tau_{r, i}+k} x_{i, t}^{r} \geq 1, \quad \forall i=1,2, \ldots, N ; \quad k=1,2, \ldots, T-\tau_{r, i} ; \quad \tau_{r, i}=\tau_{p, i} \times N_{p, i} \\
& \sum_{i=1}^{N}\left(t_{i, t}^{m} \times x_{i, t}^{m}+t_{i, t}^{r} \times x_{i, t}^{r}\right) \leq T_{t}^{0}, \quad \forall t=1,2, \ldots, T \\
& x_{t}^{p} \geq x_{i, t}^{m}, \quad \forall i=1,2, \ldots, N ; \quad t=1,2, \ldots, T \\
& x_{t}^{p} \geq x_{i, t}^{r}, \quad \forall i=1,2, \ldots, N ; \quad t=1,2, \ldots, T \\
& x_{t}^{p}, \quad x_{i, t}^{m}, \quad x_{i, t}^{r} \in\{0,1\}, \quad \forall i=1,2, \ldots, N ; \quad t=1,2, \ldots, T
\end{aligned}
$$

The objective of the railway maintenance scheduling problem is to minimize the total cost $C$ that is incurred in the planning horizon. Each element in the objective function has been previously described in this section.

The constraints in Eqs. (15) and (16) ensure that the PM activities are performed within the allowed interval $\tau_{p, i}$. The constraints in Eqs. (17) and (18) ensure that the renewal activities are performed on component $i$ when the number of PM activities reaches $N_{p, i}$. In Eqs. (16) and (18), index $k$ starts from 1 instead of 0 because when $k=0$, these constraints are very similar to those in Eqs. (15) and (17), except the upper limit of the sum on the left-hand side. Following the reasoning from Eq. (12), the upper limit in Eq. (15) is smaller than that in Eq. (16). Thus, the constraint in Eq. (16) is automatically satisfied for $k=0$. In other words, the constraint in Eq. (15) already covers Eq. (16) for the case $k=0$ and thus the index in Eq. (16) starts from 1. The constraints in Eqs. (15) and (17) have taken the current ages of components into consideration for the first maintenance and renewal. The constraint in Eq. (19) presents the effect of possession time, which guarantees that the total maintenance times of all components in a possession must be within the available possession time in each period $T_{t}^{0}$. The available possession time $T_{t}^{0}$ is given and the evaluation of possession time in each period is shown in Eq. (5). The constraints in Eqs. (20) and (21) ensure that a possession is required whenever a maintenance or renewal activity takes place, which is equivalent to Eq. (7). The constraint in Eq. (22) sets the binary conditions of decision variables.

\section{Illustrative Example}

In this section, we present an example for a railway track system consisting of $N=5$ components to illustrate the maintenance scheduling problem in a finite planning horizon with $T=12$ time periods. The input data on PM intervals, the maximum number of PMs in each life cycle, the cost and time to do a PM or renewal, the unit service life shortening cost, and the time elapsed from the last maintenance are given in Table 2. Other input data on the fixed possession cost, social-economic cost, and available possession time are provided in Table 3.

In Table 2, the number of periods elapsed from the last PM or renewal activities is the duration from the last PM or renewal to the starting time of the planning horizon. It is defined to accommodate the fact that components are generally in use for certain periods of time at the start of the planning horizon, or some maintenance activities have been performed in the past.

Generally, the service life shortening cost per unit of time (the sixth column in Table 2, $c_{i}^{s}$ ), depends on the component's renewal and maintenance costs as well as its recommended service life. The latter term can be determined based on component's PM interval $\tau_{i}^{p}$ and the maximum number of PMs in a renewal cycle $N_{p, i}$. We present the following equation to calculate $c_{i}^{s}$ :

$$
c_{i}^{s}=\frac{c_{i}^{r}+N_{p, i} c_{i}^{m}}{\tau_{p, i}\left(N_{p, i}+1\right)}
$$

The numerator on the right-hand side in Eq. (23) is the total maintenance and renewal costs between two consecutive renewals 
Table 2. Input data of components

\begin{tabular}{|c|c|c|c|c|c|c|c|c|c|}
\hline Component $(i)$ & $\begin{array}{l}\text { PM interval } \\
\text { (periods) }\end{array}$ & $\begin{array}{l}\text { Number of } \\
\text { PMs }\left(N_{p, i}\right)\end{array}$ & $\begin{array}{c}\text { Maintenance cost } \\
\text { (cost units) }\end{array}$ & $\begin{array}{c}\text { Renewal cost } \\
\text { (cost units) }\end{array}$ & Service-life shortening (cost) & $t_{i}^{m}(\mathrm{~h})$ & $t_{i}^{r}(\mathrm{~h})$ & $\tau_{p, i}^{0}$ (periods) & $N_{p, i}^{0}$ \\
\hline 1 & 4 & 9 & 2 & 6 & 0.6 & 9 & 18 & 1 & 3 \\
\hline 2 & 6 & 8 & 6 & 15 & 1.17 & 6 & 16 & 4 & 3 \\
\hline 3 & 9 & 7 & 5.5 & 20 & 0.81 & 8 & 23 & 5 & 2 \\
\hline 4 & 8 & 10 & 4 & 18 & 0.66 & 10 & 16 & 4 & 5 \\
\hline 5 & 5 & 6 & 4 & 25 & 1.4 & 3 & 12 & 4 & 2 \\
\hline
\end{tabular}

Note: $\mathrm{PM}=$ preventive maintenance.

Table 3. Possession cost and available possession time

\begin{tabular}{lc}
\hline Input parameter & Value \\
\hline Fixed possession cost (cost units) & 2 \\
Cost per customer (cost units) & 0.001 \\
Number of customers & 100 \\
Available possession time (h) & 24 \\
\hline
\end{tabular}

of component $i$, and the denominator is the component's recommended service life. The previous formula implies that the service life shortening cost of a component is an average of maintenance and renewal costs per period of use in its renewal cycle.

\section{Results and Discussion}

The results of maintenance scheduling models with and without the limitation on available possession time are investigated in terms of maintenance activity clustering, and the analysis is based on the cost and time breakdown as in the objective function in Eq. (14) and constraint in Eq. (19). In addition, the sensitivity analysis of the total cost and number of possessions over the available possession time is also performed.

In this paper, the binary linear IP model is solved using IBM CPLEX optimizer. The reason for using CPLEX is that it is able to find a true optimal solution for the linear IP model in this paper. CPLEX is commercial software, but is available for researchers to use and has been successfully applied to solve several similar linear programming models in the railway maintenance context (Budai et al. 2006; Vale et al. 2012; Vale and Ribeiro 2014; Vansteenwegen et al. 2016).

\section{Maintenance Schedules with and without Limitation of Possession Time}

First, we solve the railway maintenance scheduling problem and analyze two maintenance schedules: A-when there is no limitation on the available possession time, that is, without the limitation on possession time, and B-when there is a possession time limitation of $T^{0}=24 \mathrm{~h}$ ( 1 day). Schedule B can be obtained with the given optimization model in the previous section. The optimization model to obtain Schedule A is obtained by removing the constraint in Eq. (19) from the model. These two schedules are compared with the original schedule, which is generated by assigning the latest possible time to do a maintenance or renewal activity as the planned time to do it. The three schedules are presented in Figs. 1-3, respectively.

From Fig. 1, we can see that maintenance and renewal activities in the original schedule are spread out in the planning horizon. This is because the components have different preventive maintenance and renewal intervals. There are in total 10 possessions, and activities are rarely performed together in the same period. On the other

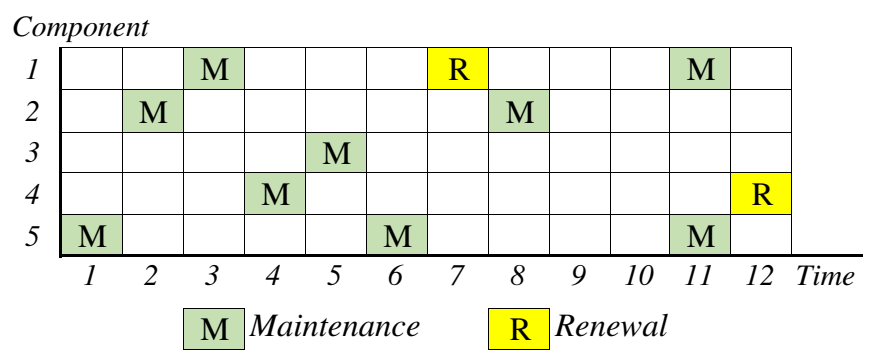

Fig. 1. Original maintenance schedule.

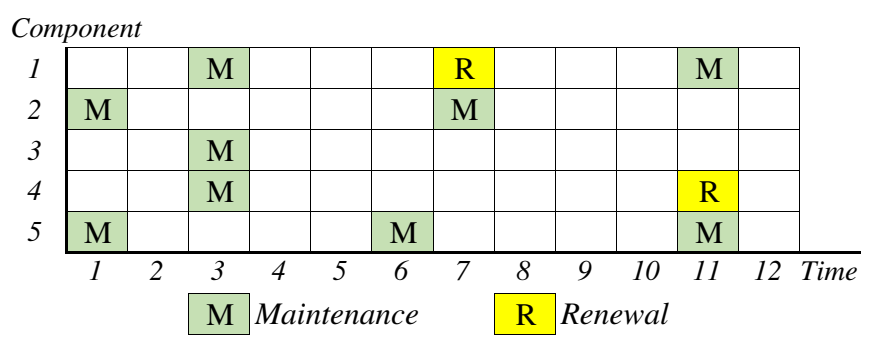

Fig. 2. Maintenance Schedule A-without limitation of possession time.

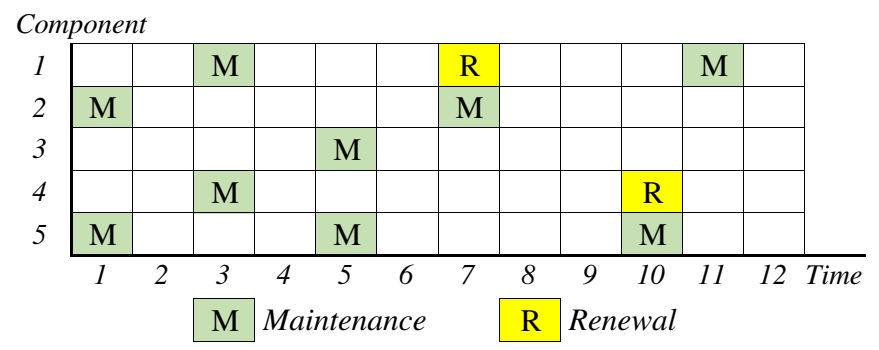

Fig. 3. Maintenance Schedule B-with 24 h limitation of possession time.

hand, many maintenance and renewal activities are clustered in Schedule A, that is, when there is no limitation on the possession time (Fig. 2). There are, in total, five possessions on the planning horizon in Periods 1, 3, 6, 7, and 11. Noticeably, three maintenance activities of Components 1, 3, and 4 are clustered in Period 3, and the renewal activity of Component 4 is also clustered with two other maintenance activities of Components 1 and 5 in Period 11. When considering the limitation of available possession time, maintenance and renewal activities in Schedule B are also combined, but not as much as in Schedule A. The four maintenance activities of Components 1, 2, 4, and 5 cannot be clustered as in Schedule A because it takes $28 \mathrm{~h}$, that is, more than $T^{0}=24 \mathrm{~h}$, to 
Table 4. Clustering of different maintenance schedules

\begin{tabular}{lcc}
\hline Schedule & $\begin{array}{c}\text { Number of } \\
\text { possessions }\end{array}$ & $\begin{array}{c}\text { Average number of } \\
\text { activities per possession }\end{array}$ \\
\hline Original & 10 & 1.10 \\
A & 5 & 2.20 \\
B & 6 & 1.83 \\
\hline
\end{tabular}

Table 5. Cost of alternative maintenance schedules (cost units)

\begin{tabular}{lccccc}
\hline Schedule & $\begin{array}{c}\text { Maintenance } \\
\text { cost }\end{array}$ & $\begin{array}{c}\text { Renewal } \\
\text { cost }\end{array}$ & $\begin{array}{c}\text { Possession } \\
\text { cost }\end{array}$ & $\begin{array}{c}\text { Service life } \\
\text { shortening cost }\end{array}$ & $\begin{array}{c}\text { Total } \\
\text { cost }\end{array}$ \\
\hline Original & 37.5 & 24 & 29.1 & - & 90.6 \\
A & 37.5 & 24 & 19.1 & 3.45 & 84.05 \\
B & 37.5 & 24 & 21.1 & 3.88 & 86.48 \\
\hline
\end{tabular}

perform these activities in the same time period. Also, each renewal of the two Components 1 and 4 can only be combined with one more maintenance activity. There are, in total, six possessions with either two maintenance activities or a maintenance and renewal activity to be clustered in Schedule B.

The clustering of maintenance activities in a schedule can be measured by two factors: the average number of activities in a possession and the total number of possessions in the schedule. The clustering of activities is high when the former factor is large and the latter one is small. These factors are calculated and tabulated in Table 4. We compare Schedule B with the original schedule and observe that the average number of activities in a possession clearly increases, by 1.7 times, and the number of possessions reduces from 10 (in the original schedule) to 6 possessions (in Schedule B).

\section{Cost and Time Analysis}

A cost analysis is performed to compare three different schedules: the original schedule, Schedule A (without limitation of possession time), and Schedule B (with limitation of possession time) to identify the similarities and differences. Four cost elements in the objective function, that is, maintenance, renewal, possession, and service life shortening costs, are calculated for each schedule and presented in Table 5 and Fig. 4.

From Table 5, we see that the original schedule has a significantly higher total cost in comparison with the other two schedules. Schedule A gives the least total cost of 84.05 cost units, whereas the total cost of Schedule B is higher at 86.48 cost units. The maintenance and renewal costs in the three schedules are similar because the number of maintenance and renewal activities are identical. The major differences are in the possession and service life shortening costs. The possession cost significantly drops when considering the clustering of maintenance activities. The original schedule requires the highest possession cost of 29.1 cost units. Schedules A and B have lower possession costs, with approximately 34.5 and $27.5 \%$ less than the original schedule, respectively. This result can be explained by the reduced number of possessions in Schedules A (5 possessions) and B (6 possessions). Regarding the service life shortening cost, Schedule B, with a limitation of possession time, results in a slightly higher cost compared to Schedule A, which implies that the activities in Schedule A are shifted to earlier periods more often in the planning horizon.

In addition, a too-long possession may not be possible due to the limitation of the available possession time. The possession times in

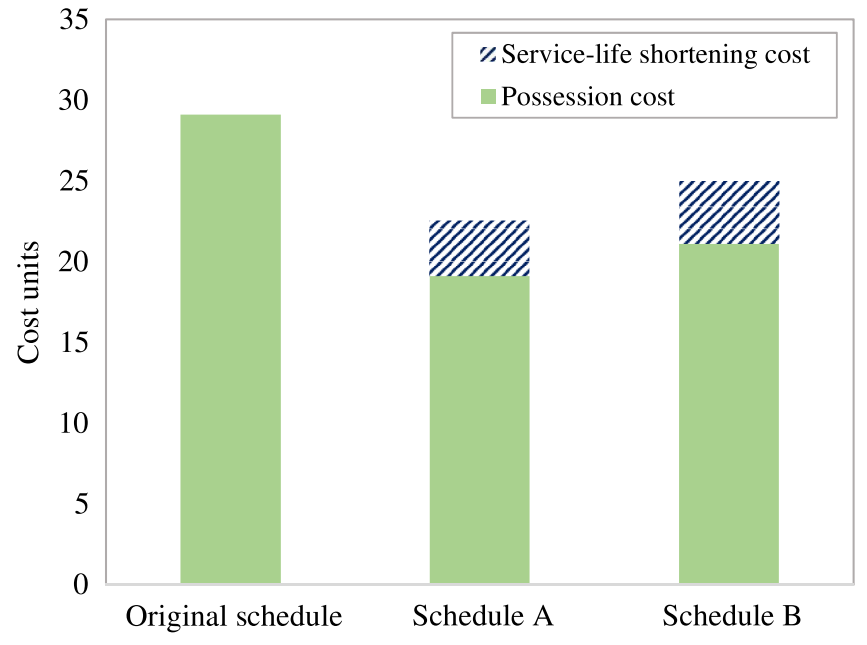

Fig. 4. Possession cost versus service-life shortening cost.

Table 6. Possession time comparisons (in hours)

\begin{tabular}{lccccccccccc}
\hline & \multicolumn{10}{c}{ Possession number } & Excess \\
\cline { 2 - 9 } Schedule & 1 & 2 & 3 & 4 & 5 & 6 & 7 & 8 & 9 & 10 & $T^{0}$ \\
\hline Original & 3 & 6 & 9 & 10 & 8 & 3 & 18 & 6 & 12 & 16 & No \\
A & 9 & 27 & 3 & 24 & 28 & N/A & N/A & N/A & N/A & N/A & Yes \\
B & 9 & 19 & 11 & 24 & 19 & 9 & N/A & N/A & N/A & N/A & No \\
\hline
\end{tabular}

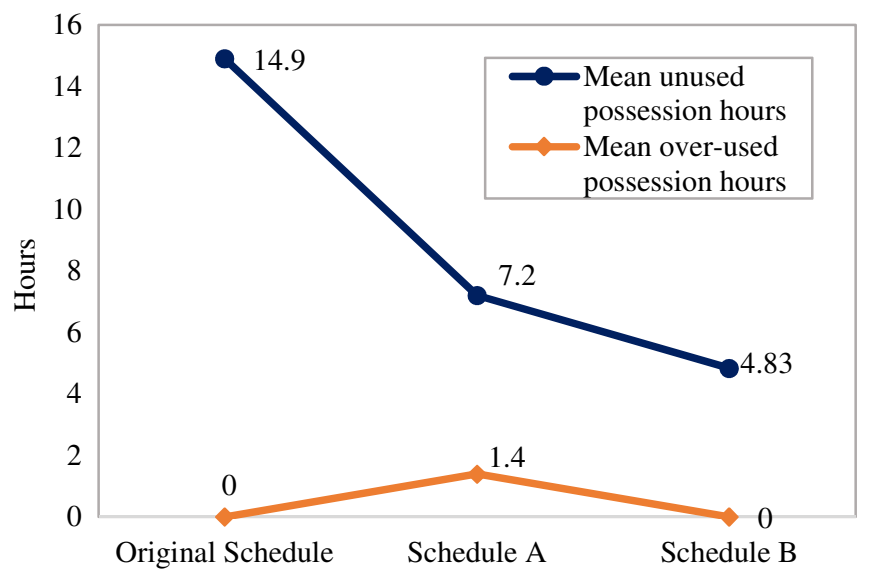

Fig. 5. Unused and overused possession time.

the three schedules are calculated and compared to the available possession time, as shown in Table 6 and Fig. 5.

Although Schedule A requires the lowest number of possessions, it ignores the limitation of available possession time and is the only schedule that violates the limitation of possession time. Two out of five possessions in Schedule A exceed the time limitation $T^{0}$, with total excessive time of $7 \mathrm{~h}$. Thus, Schedule A may not be applicable, or there will be a huge penalty when implementing it. Schedule A also has a short possession of $3 \mathrm{~h}$, which is not desirable. The original schedule requires many possessions with short durations, e.g., 3 or $6 \mathrm{~h}$, which indicate that there are opportunities for clustering and reducing the number of possessions. Meanwhile, the possession time in Schedule B is more equally distributed compared to the other two schedules. 


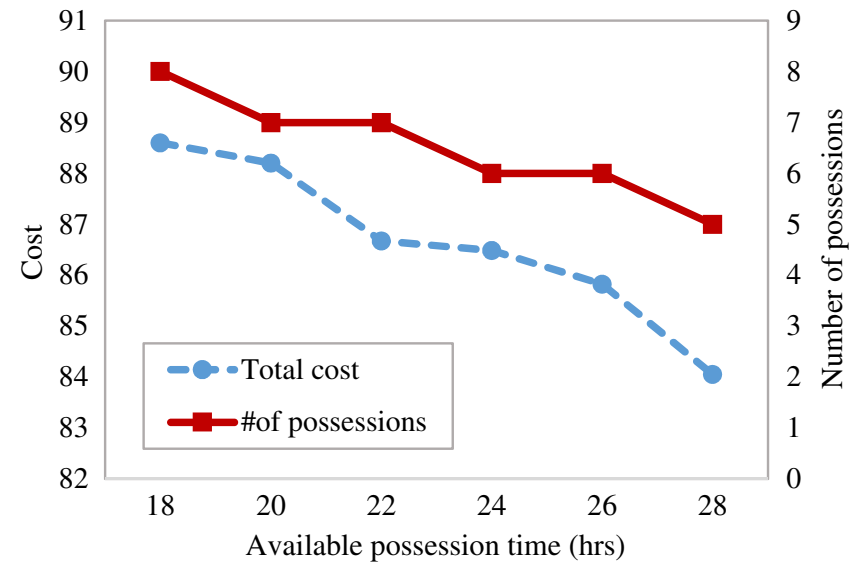

Fig. 6. Sensitivity analysis of the available possession time.

The number of possessions and possession times results in a great disparity in average unused and overused possession times of the three schedules. On average, the original schedule does not use 14.9 out of $24 \mathrm{~h}(62 \%)$, which indicates that this schedule has a very low maintenance time use, and to improve this schedule, activities should be clustered. Schedule A (without limitation of possession time) shows less unused possession time of $7.2 \mathrm{~h}(30 \%)$. However, it is the only schedule that overuses the time available for maintenance, with $1.4 \mathrm{~h}$ per possession. The schedule with a consideration of the limitation of possession time is the best schedule in terms of available time use, with only $4.8 \mathrm{~h}$ unused per possession and $0 \mathrm{~h}$ of overused available possession time.

\section{Sensitivity Analysis of the Available Possession Time}

We further investigate the effects of the available possession time $T^{0}$ on the maintenance scheduling problem. The two distinct factors characterizing a maintenance schedule, the total cost and the number of required possessions, are calculated when the available possession changes. In this experiment, $T^{0}$ is set to vary from 18 to $28 \mathrm{~h}$, and the results are presented in Fig. 6. Here, it is not possible to get a feasible schedule when the available possession time is less than $18 \mathrm{~h}$; when the available possession time is greater than $28 \mathrm{~h}$, the solution does not change compared to the one with $T^{0}$ of $28 \mathrm{~h}$. Generally, the corresponding total cost and number of possessions are negatively proportional with the available time for maintenance.

From Fig. 6, it can be seen that both the total cost and the number of possessions tend to decrease as the available possession time $T^{0}$ increases. However, the total cost gradually decreases, whereas the number of possessions sometimes remains constant when $T^{0}$ increases, for example, between $T^{0}=20$ and $T^{0}=22$; between $T^{0}=24$ and $T^{0}=26$. The reduction of the total cost indicates that a different maintenance schedule is obtained when the available possession time varies. The results of this analysis can help the maintenance decision makers in two ways:

- Select the best maintenance schedule with a specific available possession time: This is highly applicable for busy railway sections with limited flexibility on the available possession time.

- Decide whether to modify the threshold on the available possession time: This is more practical for the case in which there is some flexibility of available possession time. For example, it may be of interest to decrease the available possession time for the studied section from 24 to $22 \mathrm{~h}$ but not from 22 to $20 \mathrm{~h}$ because the additional expense in the first change
( 0.19 cost units) is notably less than that of the second change (1.53 cost units).

In this paper, due to the sensitivity of cost data, the cost data in our example are presented in terms of cost units, and we have tried to select the relative cost as close to practical data of rail track components (rails, ballast, switch, etc.) as possible. However, the cost for each type of component can vary depending on several factors, e.g., the sleeper's material, switch's size and type of turnout. The proposed model in this paper is a conceptual model that can be flexibly applied for different rail-track systems.

\section{Conclusions}

A maintenance scheduling model for several rail infrastructure components considering a limitation of possession time is presented in this paper. This model is practical for busy railway networks associated with a high demand of train operation. Several costs factors related to railway maintenance and operation have been formulated and optimized. We have analyzed the effects of the available possession time on the maintenance decisions and total cost in a finite planning horizon, and our main finding is that the limitation of available possession time can alter the resulting maintenance schedule and total cost. Furthermore, it may be worthwhile to change the limitation of possession time for the studied rail-track section. However, the detailed course of actions varies depending on the actual input costs as well as the type of railway section under investigation.

The proposed new maintenance scheduling model in this paper is for different components in a single track link. Based on the model, several research directions can be identified, as follows:

- Study the maintenance scheduling problem in a railway network context: When considering multiple components in a railway network, it is necessary to model the relationships between different track links to guarantee a smooth operation of the network. For example, when a track link is possessed for maintenance, it is not possible to possess another link because the block of both tracks will cause severe disruptions to the network operation.

- Study the methods to obtain the solution: The linear integer optimization model is currently solved by CPLEX, commercial software for solving linear optimization problems. With this, the computational time increases exponentially when the number of components and number of time periods increase. Heuristics and evolutionary computing methods are suggested for largesized problems and are recommended for future study.

\section{Notation}

The following symbols are used in this paper:

$C=$ total cost;

$C_{M}=$ maintenance cost;

$C_{P}^{e}=$ variable social-economic cost;

$C_{P}^{f}=$ fixed possession cost;

$C_{R}=$ renewal cost;

$C_{S}=$ service life shortening cost;

$c_{i, t}^{m}=$ cost of maintaining component $i$ in period $t$;

$c_{i, t}^{r}=$ cost of renewing component $i$ in period $t$;

$c_{i}^{s}=$ service life shortening cost per time period of component $i$;

$c_{P}^{e}=$ social-economic cost per customer per unit time;

$c_{P}^{0}=$ fixed setup cost occurring once per possession;

$i=$ component index; 
$N=$ number of components;

$N_{p, i}=$ number of PM activities between two renewals of component $i$;

$N_{p, i}^{0}=$ number of PM activities elapsed from last renewal of component $i$;

$N_{t}^{C}=$ expected number of customers per unit time in period $t$;

$T=$ maximum time in planning horizon;

$T_{t}=$ total maintenance and renewal time for all components in period $t$;

$T_{t}^{0}=$ available possession time in period $t$;

$t=$ time index;

$t_{i, t}^{m}=$ time of maintaining component $i$ in period $t$;

$t_{i, t}^{r}=$ time of renewing component $i$ in period $t$;

$\tau_{p, i}=$ maximum number of time periods between two PMs of component $i$; and

$\tau_{p, i}^{0}=$ number of time periods elapsed from last PM of component $i$.

\section{References}

Andrade, A., and P. Teixeira. 2011. "Biobjective optimization model for maintenance and renewal decisions related to rail track geometry." Transp. Res. Rec. 2261: 163-170. https://doi.org/10.3141/2261-19.

Budai, G. 2009. "Operations research models for scheduling railway infrastructure maintenance. Tinbergen Institute.” Accessed August 5, 2017. http://hdl.handle.net/1765/16008; http://repub.eur.nl/pub/16008/.

Budai, G., D. Huisman, and R. Dekker. 2006. "Scheduling preventive railway maintenance activities." J. Oper. Res. Soc. 57 (9): 1035-1044. https://doi.org/10.1057/palgrave.jors.2602085.

Caetano, L. F., and P. F. Teixeira. 2013. "Availability approach to soptimizing railway track renewal operations." J. Transp. Eng. 139 (9): 941-948. https://doi.org/10.1061/(ASCE)TE.1943-5436.0000575.

Caetano, L. F., and P. F. Teixeira. 2016. "Predictive maintenance model for ballast tamping." J. Transp. Eng. 142 (4): 04016006. https://doi.org/10 .1061/(ASCE)TE.1943-5436.0000825.

Cheung, B. S. N., K. P. Chow, L. C. K. Hui, and A. M. K. Yong. 1999. "Railway track possession assignment using constraint satisfaction." Eng. Appl. Artif. Intell. 12 (5): 599-611. https://doi.org/10.1016/S0952 -1976(99)00025-1.

Dao, C. D., M. Zuo, and M. Pandey. 2014. "Selective maintenance for multi-state series-parallel systems under economic dependence." Reliab. Eng. Syst. Saf. 121: 240-249. https://doi.org/10.1016/j.ress .2013.09.003.

Dekker, R., R. E. Wildeman, and F. A. Schouten. 1997. "A review of multi-component maintenance models with economic dependence." Math. Model. Oper. Res. 45 (3): 411-435. https://doi.org/10.1007 /BF01194788.

Gorman, M. F., and J. J. Kanet. 2010. "Formulation and solution approaches to the rail maintenance production gang scheduling problem." J. Transp. Eng. 136 (8): 701-708. https://doi.org/10.1061/(ASCE)0733 $-947 X(2010) 136: 8(701)$
Higgins, A. 1998. "Scheduling of railway track maintenance activities and crews." J. Oper. Res. Soc. 49 (10): 1026-1033. https://doi.org/10.1057 /palgrave.jors.2600612.

Levy, G. 2012. "Optimal planning of track work." In Proc., Cost Optimization Track Maintenance and Renewal Congress. Paris, France: Réseau ferré de France.

Lidén, T. 2015. "Railway infrastructure maintenance-A survey of planning problems and conducted research." Transp. Res. Procedia 10: 574-583. https://doi.org/10.1016/j.trpro.2015.09.011.

Lidén, T., and M. Joborn. 2016. "Dimensioning windows for railway infrastructure maintenance: Cost efficiency versus traffic impact." J. Rail Transp. Plann. Manage. 6 (1): 32-47. https://doi.org/10.1016/j .jrtpm.2016.03.002.

Nicolai, R. P., and R. Dekker. 2008. "Optimal maintenance of multicomponent systems: A review." In Complex system maintenance handbook, 263-286. London, UK: Springer.

Pargar, F., O. Kauppila, and J. Kujala. 2017. "Integrated scheduling of preventive maintenance and renewal projects for multi-unit systems with grouping and balancing." Supplement, Comput. Ind. Eng. 110: 43-58. https://doi.org/10.1016/j.cie.2017.05.024.

Peng, F., and Y. Ouyang. 2014. "Optimal clustering of railroad track maintenance jobs." Comput.-Aid. Civ. Infrastruct. Eng. 29 (4): 235-247. https://doi.org/10.1111/mice.2014.29.issue-4.

Pouryousef, H., P. Teixeira, and J. Sussman. 2010. "Track maintenance scheduling and its interactions with operations: Dedicated and mixed high-speed rail (HSR) scenarios." In Proc., 2010 Joint Rail Conf., 317-326. New York: ASME.

Uzarski, D., and S. McNeil. 1994. "Technologies for planning railroad track maintenance and renewal." J. Transp. Eng. 120 (5): 807-820. https://doi.org/10.1061/(ASCE)0733-947X(1994)120:5(807).

Vale, C., I. Ribeiro, and R. Calçada. 2012. "Integer programming to optimize tamping in railway tracks as preventive maintenance." J. Transp. Eng. 138 (1): 123-131. https://doi.org/10.1061/(ASCE)TE.1943-5436 .0000296 .

Vale, C., and I. M. Ribeiro. 2014. "Railway condition-based maintenance model with stochastic deterioration." J. Civ. Eng. Manage. 20 (5): 686-692. https://doi.org/10.3846/13923730.2013.802711.

Vansteenwegen, P., T. Dewilde, S. Burggraeve, and D. Cattrysse. 2016. "An iterative approach for reducing the impact of infrastructure maintenance on the performance of railway systems." Eur. J. Oper. Res. 252 (1): 39-53. https://doi.org/10.1016/j.ejor.2015.12.037.

Wildeman, R. E., R. Dekker, and A. C. J. M. Smit. 1997. "A dynamic policy for grouping maintenance activities." Eur. J. Oper. Res. 99 (3): 530-551. https://doi.org/10.1016/S0377-2217(97)00319-6.

Zhao, J., A. Chan, A. Stirling, and K. Madelin. 2006. "Optimizing policies of railway ballast tamping and renewal." Transp. Res. Rec. 1943: 50-56. https://doi.org/10.3141/1943-07.

Zhao, J., A. H. C. Chan, and M. P. N. Burrow. 2009. "A genetic-algorithmbased approach for scheduling the renewal of railway track components." Proc. Inst. Mech. Eng. Part F J. Rail Rapid Transit 223 (6): 533-541. https://doi.org/10.1243/09544097JRRT273.

Zorita, A. L., O. Duque, M. A. Fernández, and L. A. García-Escudero. 2010. "Determination and optimization of the maintenance frequencies in the overhead contact line system." J. Transp. Eng. 136 (11): 964-972. https://doi.org/10.1061/(ASCE)TE.1943-5436.0000166. 